\title{
ANALISIS PENUGASAN MEKANIK PADA DEALER MOTOR YAMAHA MENGGUNAKAN METODE HUNGANRIAN
}

\author{
N.Afizah ${ }^{1}$, S.Musdalifah² dan Resnawati ${ }^{3}$ \\ 1,2,3Program Studi Matematika Jurusan Matematika FMIPA Universitas Tadulako \\ Jalan Soekarno-Hatta Km. 09 Tondo, Palu 94118, Indonesia. \\ 1afizah.nur@yahoo.com, 2selvymusdalifah@yahoo.com, 3r35n4w4t1@yahoo.com
}

\begin{abstract}
The time study basically is an effort to determine the placement of the mechanical work of the length of working time spent by a mechanic in completing a job. This study aims at optimizing the placement of mechanics' length of working time to maximize the income. Variable selected is the number of mechanics 7 denoted by MK1 (Wayan), MK2 (Frendyk), MK3 (Moh.Ikram), MK4 (Sudirman), MK5 (Arif), MK6 (Dimas), MK7 (Moh.Irsal) and vehicle type denoted by 5 JM1 (Matic kaburator), JM2 (Matic Injection), JM3 (duck Injection), JM4 (duck kaburator) and JM5(Sport).The mechanics that assigned to service the bike were Wayan (MK 1), to service carburetor moped (JM4) with service time 39 minutes, Sudirman (MK4) to sevice carburetor matic motorcycle (JM1) with service time 27 minutes, Dimas (MK5) to service injection moped (JM3) with service time 32 minutes, Arif (MK6) to service injection matic motorcycle (JM2) with service time 17 minutes and Moh. Irsal (MK7) to service sport motorcycle (JM5) with service time 21 minutes. The income of Yamaha motor dealer in Januari 2016 increased after appliying hungarian method. It increased from Rp. 21. 680.000 to Rp. 24.680.000. Therefore, the improvement was Rp. 3.000.000.
\end{abstract}

Keywords : : Assignment to the Mechanic, Hungarian Method, Job Placement Analysis.

\section{ABSTRAK}

Pengukuran waktu kerja (time study) pada dasarnya merupakan suatu usaha untuk menentukan penempatan kerja mekanik dari lamanya waktu kerja yang diperlukan oleh seorang mekanik untuk menyelesaikan suatu pekerjaan. Penelitian ini bertujuan untuk penempatkan kerja mekanik yang optimal dalam rangka efisiensi waktu operasional servis dan mendapatkan penghematan waktu optimal yang dapat dicapai oleh mekanik dalam mengerjakan servis motor sehingga dapat memaksimalkan pendapatan menggunakan Metode Hungarian. Variabel yang dipilih adalah jumlah mekanik 7 orang yang dinotasikan dengan MK1 (Wayan), MK2 (Frendyk), MK3 (Moh.Ikram), MK4 (Sudirman), MK5 (Arif), MK6 (Dimas), MK7 (Moh.Irsal) dan jenis kendaraan sebanyak 5 yang dinotasikan JM1 (Matic Kaburator), JM2 (Matic Injeksi), JM3 (Bebek Injeksi), JM4 (Bebek Kaburator) dan JM5 (Sport). Penerapan penugasan optimal oleh mekanik yang ditugaskan untuk menservis motor yaitu mekanik Wayan (MK1) menservis motor Bebek Kaburator (JM4) dengan waktu servis 39 menit, mekanik Sudirman (MK4) menservis motor Matic Kaburator (JM1) dengan waktu servis 27 menit, mekanik Dimas (MK5) menservis motor Bebek Injeksi (JM3) dengan waktu servis 32 menit, mekanik Arif (MK6) menservis motor Matic Injeksi (JM2) dengan waktu servis 17 menit dan mekanik Moh.Irsal (MK7) menservis motor Sport (JM5) dengan waktu servis 21 menit. Pendapatan Dealer Motor Yamaha pada bulan Januari tahun 2016 dapat meningkat seteleh 
menggunakan Metode Hungarian sebesar Rp.24.680.000, dengan peningkatan pendapatan sebesar $R p$. 3.000.000 dari Pendapatan Dealer Motor Yamaha yaitu sebesar Rp. 21.680.000.

\section{Kata kunci : : Penugasan Mekanik, Metode Hungarian, Analisis Penempatan Kerja.}

\section{PENDAHULUAN}

\subsection{Latar Belakang}

Sepeda motor merupakan salah satu kendaraan yang paling banyak digunakan masyarakat, baik dari kalangan bawah, menengah, maupun atas. Pemilihan tersebut didasarkan atas harga beli motor yang semakin murah dan terjangkau oleh masyarakat. Yamaha merupakan salah satu merek motor unggulan yang memiliki citra yang sangat baik di mata para konsumen. Hal ini merupakan salah satu penyebab semakin meningkatnya penjualan motor Yamaha dari tahun ke tahun. Motor Yamaha memiliki beberapa jenis motor yaitu motor $C B U$ (motor jenis ini merupakan motor yang belum ada dikota Palu), motor Spotr, motor Matic dan motor Bebek. Untuk setiap jenis motornya dibedakan menjadi dua yaitu motor masih menggunakan kaburator dan yang sudah menggunakan sistem Injeksi (Agus, Wawancara).

Dealer motor Yamaha yang berada dikota palu salah satunya berada di jalan Yos Sudarso dealer ini melayani konsumen dalam melakukan penjualan maupun servis motor. Fasilitas servis tersebut diberikan sebagai salah salah satu perwujudan sikap peduli Yamaha untuk memuaskan pelanggannya. Banyaknya pelanggan Yamaha membuat kebutuhan servis semakin tinggi pula. Sementara jumlah mekanik yang menangani servis di dealer Motor terbatas. Dengan terbatasnya jumlah mekanik yang melayani servis motor, maka penempatan mekanik yang tepat sesuai dengan keahliannya itu sangat diperlukan agar mendapatkan penempatan yang optimal, sehingga dalam proses penempatan dapat dihitung berdasarkan waktu total mekanik dalam melakukan pekerjaan yang ditugaskan dan ketepatan karyawan yang efektif berdasarkan waktu pengerjaan masing-masing unit produksi (Rio Arnanda, 2007).

Saat ini, setiap mekanik cenderung menyelesaikan pekerjaan servis motor dengan kecepatan yang berbeda-beda. Akibatnya banyaknya motor yang diservis oleh setiap mekanik pada setiap bulan berbeda-beda pula. Oleh karena itu, dalam hal ini perlu dilakukan pengukuran waktu kerja, karena pengukuran waktu kerja (time study) pada dasarnya 
merupakan suatu usaha untuk menentukan penempatan kerja mekanik dari lamanya waktu kerja yang diperlukan oleh seorang mekanik untuk menyelesaikan suatu pekerjaan (Wignjosoebroto dalam Wibowo, 2008).

Penelitian ini bertujuan untuk melakukan pengukuran waktu pengerjaan servis yang optimal dan penempatan mekanik berdasarkan waktu pengerjaan yang minimum menggunakan metode hungarian. Penelitian ini akan menghasilkan pengelompokan mekanik dalam mengerjakan jenis motor dengan waktu minimum serta memperoleh data penghasilan/pendapatan dari hasil penerapan metode hungarian.

\subsection{Rumusan Masalah}

Berdasarkan latar belakang yang telah dikemukan di atas maka penulis merumuskan permasalahan yang ada yaitu bagaimana penempatan mekanik dengan penghematan waktu servis yang optimal agar dapat memaksimalkan pendapatan menggunakan Metode Hungarian.

\subsection{Tujuan Penelitian}

Tujuan yang ingin dicapai pada penulisan ini adalah :

1. Mendapatkan penempatan kerja mekanik yang optimal dalam rangka efisiensi waktu operasional servis pada Dealer Motor Yamaha.

2. Mendapatkan penghematan waktu optimal yang dapat dicapai oleh mekanik dalam mengerjakan servis motor sehingga dapat memaksimalkan pendapatan menggunakan Metode Hungarian.

\subsection{Manfaat Penelitian}

Manfaat dari penulisan ini dapat membantu perusahaan dalam melakukan penempatan kerja tenaga kerja dengan keahlian dan kemampuan di bidangnya masingmasing, agar kelangsungan hidup perusahaan dapat berjalan sesuai dengan yang diharapkan.

\subsection{Batasan Masalah}

Batasan masalah dalam penulisan tugas akhir ini adalah sebagai berikut :

1. Dalam penelitian ini mekanik pada dealer motor Yamaha diasumsikan sebagai sumber dan jenis motor diasumsikan sebagai tujuan.

2. Penelitian ini dibatasi pada waktu mekanik dalam mengerjakan servis ringan berkala. 


\section{TINJAUAN PUSTAKA}

\subsection{Metode Hungarian}

Masalah penugasan (assignment problem) merupakan kasus yang sering ditemui dalam penanganan tenaga kerja. Salah satu metode yang digunakan untuk masalah penugasan optimal adalah metode Hungarian, (Taha dalam Marline Paendong dan Jantje D. Prang, 2011).

Kasus yang dapat diselesaikan dengan menggunakan Metode Hungarian adalah kasus-kasus penugasan seperti penugasan beberapa karyawan untuk menyelesaikan beberapa pekerjaan. Masalah dalam metode hungarian merupakan kasus khusus dari masalah penugasan, dimana 1 sumber ditugaskan 1 tujuan sedemikian sehingga didapatkan keuntungan yang optimal.

Biasanya yang dimaksud sumber adalah karyawan, sedangkan yang dimaksud tujuan adalah pekerjaan. Jadi, dalam hal ini ada 1 karyawan yang mengerjakan 1 pekerjaan, dan dimana apabila karyawan $i(i=1,2, \ldots, m)$ mengerjakan pekerjaan $j(j=1,2, \ldots, n)$ akan muncul waktu penugsan $c_{i j}$ (Dimyanti dalam Pika Palentina Manurung, 2012).

Secara matematis masalah penugasan pada Metode Hungarian dapat dinyatakan dalam bentuk variabel keputusan $x_{i j}$ yaitu :

$x_{i j}=1$, apabila objek $i$ ditugaskan untuk tugas $j$

$x_{i j}=0$, apabila objek $i$ tidak ditugaskan untuk tugas $j$

Dengan demikian, model persoalan penugasan pada Metode Hungarian adalah:

Fungsi tujuan :

$f=\sum_{i=1}^{m} \sum_{j=1}^{n} c_{i j} x_{i j}$

Dengan fungsi kendala :

$\sum_{i=1}^{n} x_{i j}=1 \quad i=1,2, \ldots, m$

$\sum_{j=1}^{m} x_{i j}=1 \quad j=1,2, \ldots, n$ dimana $x_{i j}=0$ atau 1

Dimana :

$f=$ fungsi tujuan 
$x_{i j}=$ variabel keputusan

$c_{i j}=$ nilai kontribusi objek $\mathrm{i}$ terhadap tugas $\mathrm{j}$

$m=$ jumlah objek (individu atau sumber daya)

$n=$ jumlah tugas/pkerjaan yang akan diselesaikan.

$i=$ karyawan

$j=$ tugas/pekerjaan

Metode Hungarian adalah metode yang memodifikasi baris dan kolom dalam matriks efektifitas sampai muncul komponen nol tunggal dalam setiap baris atau kolom yang dapat dipilih sebagai alokasi penugasan. Semua alokasi penugasan yang dibuat adalah alokasi yang optimal, dan saat diterapkan pada matriks efektifitas awal, maka akan memberikan hasil penugasan yang paling minimum(Suyadi Prawisentono dalam Syifa Rizkyka Taufikqoh, 2013).

Syarat-syarat yang dipenuhi dalam menyelesaikan masalah dengan mengunakan Metode Hungarian adalah sebagai berikut :

1. Matriks biaya harus merupakan matriks kuadratis, maksudnya adalah bahwa banyaknya tugas (assignment) sama dengan penerima (assignee).

2. Entri matriks biaya harus merupakan bilangan bulat, karna lebih praktis digunakan dan lebih mudah, sedangakan untuk entri yang tidak bulat matriks biayanya dikalikan dengan pangkat sepuluh.

3. Metode Hunagarian digunakan utuk menyelesaiakan masalah minimasi, karna inti dari Metode Hungarian adalah untuk memperoleh elemen biaya yang minimum, sedangkan untuk masalah maksimasi, matriks biaya diubah menjadi masalah minimasi dengan mengalikan setiap entri dari matriks biaya dengan -1 (Anton, $\mathrm{H}$. dalam Mulyati, 2009).

\subsection{Metode Hungarian untuk Kasus Maksimasi Pendapatan}

Metode Hungarian untuk masalah maksimasi dapat diaplikasikan kedalam suatu masalah penetapan yang tujuannya adalah memaksimalkan pendapatan. Adapun langkahlangkah untuk menyelesaikan masalah maksimasi dengan Metode Hungarian adalah sebagai berikut :1.Membuat matriks biaya, 2.Mengalikan semua entri pada baris dan kolom dengan -1 , 3.Menentukan nilai terbesar, pada setiap baris lalu kurangkan semua entri pada setiap baris tersebut dengan entri terbesar, 4.Jika pada kolom belum memiliki entri nol, maka tentukan nilai terkecil kemudian kurangkan setiap entri pada kolom tersebut dengan nilai terkecil, 5.Tarik garis yang memiliki entri nol yang paling banyak, 6. Uji Optimalisasi yaitu, jika jumlah garis yang ditarik belum sama dengan jumlah baris dan kolom maka masalah penugasan tersebut belum optimal, 7.Revisi tabel dengan Menentukan entri terkecil yang 
tidak tertutupi oleh garis, lalu semua entri yang tidak tertutupi oleh garis tersebut dikurangkan dengan entri terkecil, sedangkan nilai yang terletak antara perpotongan garis ditambahkan dengan entri terkecil, 8.Kembali kelangkah 5 (Tarik garis yang memiliki entri nol yang paling banyak). (Eliyani dalam Mulyati, 2009)

\subsection{Metode Hungarian untuk Kasus Meminimumkan Waktu}

Langkah-langkah metode Hungarian untuk kasus minimasi adalah: 1. Membuat matriks biaya, 2.Menentukan entri terkecil untuk setiap kolom. Kurangka semua entri tersebut dengan entri terkecil, 3.Lakukan pengurangan pada entri yang belum memiliki entri nol, tentukan entri terkecil dan kurangkan dengan entri tersebut, 4.Tarik garis yang memiliki entri nol paling banyak , 5.Uji Optimalisasi, jika jumlah garis yang ditarik belum sama dengan jumlah baris dan kolom maka masalah penugasan tersebut belum optimal, 6. Revisi tabel jiika belum optimal, maka tentukan entri terkecil yang tidak ditutupi oleh garis, kurangkan semua entri tersebut dengan entri terkecil dan tambahkan entri tersebut dengan entri yang terletak antara perpotongan garis, 7. Kembali kelangkah 4 (Tarik garis yang memiliki entri nol paling banyak). (Eliyani dalam Mulyati, 2009)

\section{METODE PENELITIAN}

\subsection{Lokasi dan Tempat Penelitian}

Penelitian ini dilakukan disalah satu dealer motor Yamaha yang berada di Jalan Yos Sudarso Palu.

\subsection{Jenis Data}

Jenis data yang akan digunakan dalam penelitian ini adalah data kualitatif dan kuantitatif, yaitu berupa nama mekanik dan lama waktu mekanik dalam menservis motor.

\subsection{Sumber Data}

Sumber data yang digunakan dalam penelitian ini adalah data primer yaitu yaitu data yang diperoleh dari hasil wawancara langsung dengan kepala mekanik dan 7 oarag mekanik yang bekerja didealer motor Yamaha di Jalan Yos Soedarso.

\subsection{Prosedur Penelitian}

1. Mulai penelitian

2. Pengambilan data

3. Membuat matriks masalah penugasan

4. Penerapan Metodee Hungarian

5. Analisis Penugasan 

6. Hasil
7. Kesimpulan
8. Selesai .

\section{HASIL DAN PEMBAHASAN}

\subsection{Data dan Profil Objek Penelitian}

Penelitian ini dilakukan di salah satu Dealer Motor Yamaha yang berada di kota Palu yang tepatnya berada dijalan Yos Sudarso. Dealer Motor Yamaha ini selain menjual motor juga melayani servis motor, ada tiga jenis servis yang berada di dealer ini yaitu servis berkala, servis ringan dan servis berat.

Dealer motor Yamaha ini melayani servis ringan berkala untuk setiap jenis motor yang berbeda baik motor yang menggunakan kaburator ataupun yang sudah menggunakan injeksi. Jenis motor yang ada yaitu Matic Kaburator disimbolkan (JM1), Matic Injeksi disimbolkan (JM2), Bebek Injeksi disimbolkan (JM3), Bebek Kaburator (JM4), dan Sport (JM5). Sedangkan untuk mekanik yang ditugaskan untuk menservis motor berjumlah 7 orang yaitu Wayan disimbolkan (MK1), Frendyk disimbolkan (MK2), Moh.lkram disimbolkan (MK3), Sudiman disimbolkan (MK4), Arif disimbolkan (MK5), Dimas disimbolkan (MK6), Moh.Irsal disimbolkan (MK7). Karena pada kasus ini banyaknya jenis motor tidak sama dengan jumlah mekanik maka pada jenis motor ditambahkan variabel dummy dimana untuk variabel dummy pertama disimbolkan (JM6) variabel dummy kedua disimbolkan (JM7).

Tabel 1 : Waktu servis ringan yang dibutuhkan setiap mekanik dalam menyelasaikan setiap pekerjaan, dalam satuan menit.

\begin{tabular}{|c|c|c|c|c|c|c|c|}
\hline \multirow{2}{*}{$\begin{array}{c}\text { Nama } \\
\text { Mekanik }\end{array}$} & $\begin{array}{c}\text { Matic } \\
\text { kaburator }\end{array}$ & $\begin{array}{c}\text { Matic } \\
\text { Injeksi }\end{array}$ & $\begin{array}{c}\text { Bebek } \\
\text { Injeksi }\end{array}$ & $\begin{array}{c}\text { Bebek } \\
\text { kaburburator }\end{array}$ & Sport & Dummy1 & Dummy2 \\
\hline Wayan & 26 & 25 & 37 & 39 & 41 & 0 & 0 \\
\hline Frendyk & 28 & 24 & 40 & 43 & 40 & 0 & 0 \\
\hline Moh.ikram & 29 & 27 & 41 & 43 & 30 & 0 & 0 \\
\hline Sudirman & 27 & 25 & 40 & 45 & 32 & 0 & 0 \\
\hline Arif & 30 & 25 & 32 & 35 & 30 & 0 & 0 \\
\hline Dimas & 23 & 17 & 31 & 35 & 24 & 0 & 0 \\
\hline Moh.Irsal & 30 & 22 & 25 & 34 & 21 & 0 & 0 \\
\hline
\end{tabular}




\subsection{Penerapan Metode Hungarian}

Berdasarkan waktu penugasan pada tabel 1, maka dapat dilihat hasil penererapan dengan tahapan metode Hungarian mulai dari membentuk matriks efektifitas sampai diperoleh penugasan optimum sebagai berikut:

Tabel 2: Penugasan Optimum

\begin{tabular}{|c|r|r|r|r|r|r|r|}
\hline Mekanik & JM1 & JM2 & JM3 & JM4 & JM5 & JM6 & JM7 \\
\hline MK1 & 0 & 2 & 1 & 0 & 12 & 1 & 1 \\
\hline MK2 & 1 & 0 & 3 & 3 & 10 & 0 & 0 \\
\hline MK3 & 2 & 3 & 4 & 3 & 0 & 0 & 0 \\
\hline MK4 & 0 & 1 & 3 & 5 & 2 & 0 & 0 \\
\hline MK5 & 8 & 6 & 0 & 0 & 5 & 5 & 5 \\
\hline MK6 & 3 & 0 & 1 & 2 & 1 & 7 & 7 \\
\hline MK7 & 12 & 7 & 0 & 3 & 0 & 9 & 9 \\
\hline
\end{tabular}

\begin{tabular}{|c|c|c|c|c|c|c|c|}
\hline Mekanik & JM1 & JM2 & JM3 & JM4 & JM5 & JM6 & JM7 \\
\hline MK1 & 0 & 2 & 1 & 0 & 12 & 1 & 1 \\
\hline MK2 & 1 & 0 & 3 & 3 & 10 & 0 & 0 \\
\hline MK3 & 2 & 3 & 4 & 3 & 0 & 0 & 0 \\
\hline MK4 & 0 & 1 & 3 & 5 & 2 & 0 & 0 \\
\hline MK5 & 8 & 6 & 0 & 0 & 5 & 5 & 5 \\
\hline MK6 & 3 & 0 & 1 & 2 & 1 & 7 & 7 \\
\hline MK7 & 12 & 7 & 0 & 3 & 0 & 9 & 9 \\
\hline
\end{tabular}

Berdasarkan tabel penugasan optimal oleh mekanik yang ditugaskan untuk menservis motor yaitu mekanik MK1 menservis motor JM4 dengan waktu servis 39 menit, mekanik MK2 menservis motor JM7 dengan waktu servis 0 menit, mekanik MK3 menservis motor JM6 dengan waktu servis 0 menit, mekanik MK4 menservis motor JM1 dengan waktu servis 27 menit, mekanik MK5 menservis motor JM3 dengan waktu servis 32 menit, mekanik MK6 menservis motor JM2 dengan waktu servis 17 menit dan mekanik MK7 menservis motor JM7 dengan waktu servis 21 menit, dari hasil pemaparan untuk mekanik MK2 dan MK3 tidak 
ditugaskan untuk melakukan servis ringan berkala karna untuk jenis motor JM6 dan JM7 merupakan variabel dummy atau variabel tambahan.

Berdasarkan hasil penugasan mekanik pada pengoptimalan di atas agar semua mekanik dapat mengerjakan servis ringan berkala untuk setiap jenis motor, maka dapat diterapkan alternatif lain yaitu denga cara mengelompokan mekanik.

Tabel 3: Pengelompokan Mekanik

\begin{tabular}{|l|l|l|l|}
\hline No & Jenis Motor & $\begin{array}{l}\text { Kelompok penugasan } \\
\text { Mekanik }\end{array}$ & Waktu Servis \\
\hline 1 & Matic Kaburator (JM1) & $\begin{array}{l}\text { 1) Wayan (MK1) } \\
\text { 2) Sudirman (MK4) }\end{array}$ & $\begin{array}{l}\text { 1) } 26 \text { menit } \\
\text { 2) } 27 \text { menit }\end{array}$ \\
\hline 2 & Matic Injeksi (JM2) & $\begin{array}{l}\text { 1) Frendyk (MK2) } \\
\text { 2) Arif (MK6) }\end{array}$ & 1) 24 menit \\
\hline 3 & Bebek Injeksi (JM3) & 1) Dimas (MK5) & 1) 35 menit \\
\hline 4 & Bebek Kaburator (JM4) & 2) Moh.Irsal (MK7) & 2) 34 menit \\
\hline 5 & 2) Dimas (MK5) & 1) 39 menit \\
\hline \multirow{2}{*}{5} & 2port (JM5) & 1) Moh.Irsal (MK7) & 1) 21 menit \\
\hline
\end{tabular}

\subsection{Analisis Kemungkinan Penugasan}

Setelah mendapatkan pengelompokan penugasan mekanik dengan menggunakan Metode Hungarian dalam melakukan servis ringan berkala pada Dealer Motor Yamaha, maka dapat diasumsikan kemungkinan-kemukinan yang terjadi, yaitu :

1. Analisin kemungkinan pertama

Jika banyaknya jenis motor yang sama datang untuk melakukan servis ringan berkala lebih banyak dari jumlah mekanik yang telah ditugaskan maka mekanik lain dapat ditugaskan

2. Analisis kemungkinan kedua

Jika banyaknya jenis motor yang sama datang untuk melakukan servis ringan berkala lebih banyak dari jumlah mekanik yang telah ditugaskan dan mekanik yang ditugaskan berdasarkan analisis kemungkinan pertama juga sedang mengerjakan jenis motor yang sama maka mekanik lain yang ditugaskan 
3. Diasumsikan jika semua jenis motor yang sama datang untuk melakukan servis ringan berkala.

maka dapat diterapkan kembali penempatan penugasan mekanik dengan cara menggunakan Metode Hungarian berdasarkan pengelompokan penugasan mekanik, maka didapatkan yaitu:

Tabel 4: Hasil Analisis Kemungkinan Penugasan

\begin{tabular}{|c|c|c|c|c|}
\hline Jenis Motor & $\begin{array}{l}\text { Kelompok penugasan } \\
\text { Mekanik }\end{array}$ & $\begin{array}{l}\text { Analisis kemungkinan } \\
\text { pertama }\end{array}$ & $\begin{array}{l}\text { Analisis } \\
\text { kemungkinan } \\
\text { kedua }\end{array}$ & $\begin{array}{l}\text { Analisis } \\
\text { kemungkinan } \\
\text { ketiga }\end{array}$ \\
\hline $\begin{array}{l}\text { Matic Kaburator } \\
\text { (JM1) }\end{array}$ & $\begin{array}{l}\text { 1) Wayan (MK1) } \\
\text { 2) Sudirman (MK4) }\end{array}$ & $\begin{array}{l}\text { 1)Frendyk(MK2) } \\
\text { 2)Moh.Ikram(MK3) }\end{array}$ & Dimas(MK5) & $\begin{array}{l}\text { Semua mekanik } \\
\text { dapat } \\
\text { mengerjakannya }\end{array}$ \\
\hline $\begin{array}{ll}\text { Matic } & \text { Injeksi } \\
(\mathrm{JM} 2) & \end{array}$ & $\begin{array}{l}\text { 1) Frendyk (MK2) } \\
\text { 2) Arif (MK6) }\end{array}$ & $\begin{array}{l}\text { 1)Moh.Ikram (MK3) } \\
\text { 2) Sudirman (MK4) }\end{array}$ & $\begin{array}{l}\text { 1)Wayan(MK) } \\
\text { 2)Dimas(MK) }\end{array}$ & $\begin{array}{l}\text { Semua mekanik } \\
\text { dapat } \\
\text { mengerjakannya }\end{array}$ \\
\hline $\begin{array}{l}\text { Bebek } \\
\text { Kaburator } \\
\text { (JM3) }\end{array}$ & $\begin{array}{l}\text { 1) Dimas (MK5) } \\
\text { 2) Moh.Irsal (MK7) }\end{array}$ & Arif(MK6) & Wayan (MK1) & $\begin{array}{l}\text { Semua mekanik } \\
\text { dapat } \\
\text { mengerjakannya }\end{array}$ \\
\hline $\begin{array}{l}\text { Bebek Injeksi } \\
\text { (JM4) }\end{array}$ & $\begin{array}{l}\text { 1) Wayan (MK1) } \\
\text { 2) Dimas (MK5) }\end{array}$ & $\begin{array}{l}\text { 1)Moh.Ikram (MK3) } \\
\text { 2)Arif(MK6) } \\
\text { 3)Moh.Irsal (MK7) }\end{array}$ & - & $\begin{array}{l}\text { Semua mekanik } \\
\text { dapat } \\
\text { mengerjakannya }\end{array}$ \\
\hline Sport(JM5) & $\begin{array}{l}\text { 1) Moh.Irsal(MK7 } \\
\text { 2) Moh. Ikram(MK3) }\end{array}$ & $\begin{array}{l}\text { 1)Wayan (MK1) } \\
\text { 2) Dimas(MK5) }\end{array}$ & Arif (MK6 & $\begin{array}{l}\text { Semua mekanik } \\
\text { dapat } \\
\text { mengerjakannya }\end{array}$ \\
\hline
\end{tabular}

\subsection{Analisis Penugasan Mekanik}

Setelah melakukan pengelompokan penugasan dan menganalisis kemungkinankemungkinan penugasan mekanik dengan menggunakan Metode Hungarian, jumlah kendaraaan yang diservis mekanik berdasarkan pengelompokan penugasan tersebut yaitu 
Tabel 5 : Jumlah kendaraan yang dapat diservis setelah menggunakan metode hungarian pada bulan Januari(unit)

\begin{tabular}{|c|c|c|c|c|c|}
\cline { 1 - 4 } \begin{tabular}{c} 
Mekanik \\
\cline { 1 - 4 } Jenis Motor
\end{tabular} & JM1 & JM2 & JM3 & JM4 & JM5 \\
\cline { 1 - 5 } MK1 & 22 & 24 & 15 & 24 & 9 \\
\hline MK2 & 17 & 25 & 17 & 20 & 7 \\
\hline MK3 & 18 & 24 & 19 & 18 & 14 \\
\hline MK4 & 20 & 23 & 18 & 16 & 10 \\
\hline MK5 & 16 & 22 & 22 & 24 & 12 \\
\hline MK6 & 15 & 27 & 19 & 19 & 10 \\
\hline MK7 & 16 & 22 & 21 & 20 & 15 \\
\hline Jumlah & 124 & 144 & 131 & 141 & 77 \\
\hline Total & & 617 & \\
\hline
\end{tabular}

Setelah menganalisis penugasan mekanik dengan mengelompokan mekanik untuk setiap jenis motor, maka didapatkkan hasil analisisnya yaitu :

Tabel 6 : Hasil analisis berdasarkan pengelompokan penugasan mekanik.

\begin{tabular}{|c|c|c|c|c|c|c|}
\hline Jenis Motor & $\begin{array}{l}\text { Kelompok } \\
\text { penugasan } \\
\text { Mekanik }\end{array}$ & $\begin{array}{l}\text { Waktu } \\
\text { Servis } \\
\text { rata-rata/ } \\
1 \text { Unit }\end{array}$ & $\begin{array}{l}\text { Jumlah } \\
\text { Kendaraan } \\
\text { Yang } \\
\text { Diservis/ } \\
\text { Hari } \\
\end{array}$ & $\begin{array}{l}\text { Waktu } \\
\text { yang } \\
\text { dibutuhkan/ } \\
\text { hari }\end{array}$ & $\begin{array}{l}\text { Waktu } \\
\text { yang } \\
\text { dibutuhkan } \\
\text { /sepekan }\end{array}$ & $\begin{array}{l}\text { Waktu } \\
\text { luang } \\
\text { /sepe } \\
\text { kan }\end{array}$ \\
\hline Matic Kaburator & $\begin{array}{l}\text { 1) Wayan } \\
\text { 2) Sudirman }\end{array}$ & 27 menit & $\begin{array}{l}\text { 1) } 2 \text { Unit } \\
\text { 2) } 2 \text { unit }\end{array}$ & 54 menit & $\begin{array}{l}324 \\
\text { menit }\end{array}$ & $\begin{array}{l}2136 \\
\text { menit }\end{array}$ \\
\hline Matic Injeksi & $\begin{array}{l}\text { 1) Frendyk } \\
\text { 2) Arif }\end{array}$ & 21 menit & $\begin{array}{l}\text { 1) } 3 \text { unit } \\
\text { 2) } 3 \text { unit }\end{array}$ & 63 menit & 378 menit & $\begin{array}{l}2082 \\
\text { memit }\end{array}$ \\
\hline Bebek Injeksi & $\begin{array}{l}\text { 1) Dimas } \\
\text { 2) Moh.Irsal }\end{array}$ & 26 menit & $\begin{array}{l}\text { 1) } 3 \text { Unit } \\
\text { 2) } 3 \text { Unit }\end{array}$ & 78 menit & 468 menit & $\begin{array}{l}1992 \\
\text { menit }\end{array}$ \\
\hline $\begin{array}{l}\text { Bebek } \\
\text { Kaburator }\end{array}$ & $\begin{array}{l}\text { 1) Wayan } \\
\text { 2) Dimas }\end{array}$ & 37 menit & $\begin{array}{l}\text { 1) } 3 \text { Unit } \\
\text { 2) } 3 \text { Unit }\end{array}$ & 111 menit & 666 menit & $\begin{array}{l}1794 \\
\text { menit }\end{array}$ \\
\hline Sport & $\begin{array}{l}\text { 1) Moh.Irsal } \\
\text { 2) Moh.Ikram }\end{array}$ & 26 menit & $\begin{array}{l}\text { 1) } 2 \text { Unit } \\
\text { 2)2 unit }\end{array}$ & 52 menit & 312 menit & $\begin{array}{l}2148 \\
\text { menit }\end{array}$ \\
\hline Total & & 137 menit & 26 Unit & 358 menit & 2148menit & $\begin{array}{l}10152 \\
\text { menit }\end{array}$ \\
\hline
\end{tabular}

Dari waktu rata-rata setiap kelompok mekanik menyelesaikan setiap jenis motor yang ditugaskan, kelompok mekanik tersebut hanya memerlukan waktu 324 menit untuk jenis 
motor Matic Kaburator, 378 menit untuk jenis motor Matic Injeksi, 468 menit unuk motor Bebek Injeksi, 666 menit unuk jenis motor Bebek Kaburator dan 312 menit untuk jenis motor Sport setiap pekannya.

Dilihat dari waktu kerja mekanik 41 jam dalam sepekan dengan waktu yang dibutuhkan mekanik dalam menservis ringan berkala memerlukan waktu 2148 menit atau 36 jam setiap pekannya maka terdapat banyak waktu luang 10152 menit mekanik yang ditugaskan apabila hanya untuk melakukan servis ringan berkala, namun pada kasus di atas terdapat pengelompokan penugasan mekanik dengan mekanik yang sama tetapi mengerjakan jenis motor yang berbeda.

Dealer yamaha yang berada di jalan Yos Sudarso bukan hanya menyediakan jasa untuk melakukan servis ringan berkala saja, ada tiga jenis servis yang disediakan yaitu servis ringan berkala, servis ringan dan servis berat sehingga waktu kerja yang disediakan pada dealer 41 jam setiap pekannya mencakup untuk semua jasa servis yang ada di dealer tersebut.

Untuk jasa servis ringan berkala waktu yang dibutuhkan untuk setiap pekannya adalah 2148 menit dalam sepekan, sedangkan untuk jasa servis ringan waktu yang dibutuhkan untuk mengerjakan adalah 7-15 menit unrtuk satu jenis servis ringan dan jasa untuk servis berat memakan waktu 2-3 jam untuk satu jenis servis berat.

\subsection{Analisis Pendapatan}

Dengan menganalisis penerapan metode hungarian dengan meminimalkan waktu servis mekanik dalam mengerjakan servis ringan berkala untuk satu jenis motor dengan menggunakan Metode Hungarian terlihat perbedaan dari jumlah kendaraan pada sebelum dan setelah menggunakan Metode Hungarian jumlah kendaraan yang diservis dapat meningkat, dari jumlah kendaraan 542 unit kendaraan yang dapat diservis ringan berkala sebelum menggunakan Metode Hungarian dapat menjadi 617 unit setelah menggunakan Metode Hungarian pada bulan Januari.

Perbedaan dari jumlah kendaraan yang datang sebelum dan setelah menggunakan Metode Hungarian tentu berpengaruh terhadap pendapatan pada Dealer Motor Yamaha tersebut, dengan biaya yang sama yaitu Rp.40.000 untuk satu jenis motor maka didapatkan pendapatan Dealer Motor Yamaha adalah :

Pendapatan sebelum menggunakan Metode Hungarian dengan jumlah kendaraan 542 unit maka didapatkan : $542 \times R p .40 .000=R p .21 .680 .000$ 
$\checkmark \quad$ Pendapatan setelah menggunakan Metode Hungarian dengan prediksi jumlah kendaraan 617 unit maka didapatkan : $617 \times R p .40 .000=R p .24 .680 .000$

$\checkmark \quad$ Dengan peningkatan pendapatan sebelum dan sesudah Menggunakan Metode Hungarian adalah Rp.24.680.000 - Rp.21.680.000 = Rp.3.000.000

\section{KESIMPULAN}

Berdasarkan hasil dari pembahasan maka dapat diambil kesimpulan sebagai berikut :

1. Penerapan penugasan optimal oleh mekanik yang ditugaskan untuk menservis motor yaitu mekanik Wayan (MK1) menservis motor Bebek Kaburator (JM4) dengan waktu servis 39 menit, mekanik Sudirman (MK4) menservis motor Matic Kaburator(JM1) dengan waktu servis 27 menit, mekanik Dimas (MK5) menservis motor Bebek Injeksi (JM3) dengan waktu servis 32 menit, mekanik Arif (MK6) menservis motor Matic Injeksi (JM2) dengan waktu servis 17 menit dan mekanik Moh.Irsal (MK7) menservis motor Sport (JM5) dengan waktu servis 21 menit.

2. Setelah menganalisis kemungkinan-kemungkina maka dapat disempulkan semua mekenik dapat menservis setiap jenis motor jika mekanik yang ditugaskan telah mengerjakan jenis motor yang telah ditentukan.

3. Dengan meminimalkan waktu servis mekanik maka berdampak pada pendapatan Dealer Motor Yamaha karna jumlah motor yang diservis semakin banyak. Jumlah pendapatan Dealer Motor Yamaha di bulan Januari dapat meningkat dari pendapatan sebelum penerapan menggunakan Metode Hungarian adalah $R p .21 .680 .000$ dan sesudah penerapan menggunakan Metode Hungarian adalah Rp.24.680.000 dengan penambahan pendapatan sebesar Rp. 3000.000 .

\section{DAFTAR PUSTAKA}

[1] Mulyati, 2009, Meode Hungarian dalam Kasus Maksimasi dan Minimasi, Program Studi Matematika FMIPA,Universitas Tadulako

[2] Paendong,M dan D.Prang,J, 2011, Optimalisasi Pembagian Tugas Karyawan

Menggunakan Metode Hungarian,Program Studi Matematika FMIPA, Universitas Samratulangi Manado.

[3] Palentina Pika,M, 2012, Optimalisasi Pendapatan Toko .Kue Golden Dengan Menggunakan Metode Hungarian, Program Studi Matematika FMIPA, Universitas Tadulako 
[4] Rio Arnanda, 2007, Analisis Penempatan Karyawan Pada Bengkel Mobil Dewi Motor Dengan Menggunakan Metode Hungarian, Fakultas Ekonomi, Universitas Gunadarma.

[5] Rizkyka,S, 2013, Analisis Penempatan SDM dengan Metode Hungarian pada Rumah Potong Hewan HM.Taufik, Fakultas Ekonomi, Universitas Gunadarma.

[6] Wibowo, 2008, Pengukuran Waktu Standar Pekerjaan Servis Motor di Pt. Bandung Raya Motor Untuk Meningkatkan Produktivitas, Fakutas Ekonomi, Universitas Kristen Maranatha. 